\title{
A Critical Role for Purinergic Signalling in the Mechanisms Underlying Generation of BOLD fMRI Responses
}

\author{
Jack A. Wells, ${ }^{1 \star}$ Isabel N. Christie, ${ }^{1,2 \star}$ Patrick S. Hosford, ${ }^{2}$ Robert T.R. Huckstepp, ${ }^{2}$ Plamena R. Angelova, ${ }^{3}$ \\ Pirkko Vihko, ${ }^{4}$ Simon C. Cork, ${ }^{2}$ Andrey Y. Abramov, ${ }^{3}$ Anja G. Teschemacher, ${ }^{5}$ Sergey Kasparov, ${ }^{5} \dagger$ Mark F. Lythgoe, ${ }^{1} \dagger$ \\ and Alexander V. Gourine ${ }^{2} \dagger$ \\ ${ }^{1}$ University College London Centre for Advanced Biomedical Imaging, Division of Medicine, University College London, London, WC1E 6DD, United \\ Kingdom, ${ }^{2}$ Centre for Cardiovascular and Metabolic Neuroscience, Neuroscience, Physiology and Pharmacology, University College London, London, \\ WC1E 6BT, United Kingdom, ${ }^{3}$ Institute of Neurology, University College London, London, WC1N 3BG, United Kingdom, ${ }^{4}$ Department of Clinical \\ Chemistry, University of Helsinki and Helsinki University Hospital Laboratory, 00100 Helsinki, Finland, and ${ }^{5}$ School of Physiology and Pharmacology, \\ University of Bristol, Bristol, BS8 1TD, United Kingdom
}

The mechanisms of neurovascular coupling underlying generation of BOLD fMRI signals remain incompletely understood. It has been proposed that release of vasoactive substances by astrocytes couples neuronal activity to changes in cerebrovascular blood flow. However, the role of astrocytes in fMRI responses remains controversial. Astrocytes communicate via release of ATP, and here we tested the hypothesis that purinergic signaling plays a role in the mechanisms underlying fMRI. An established fMRI paradigm was used to trigger BOLD responses in the forepaw region of the somatosensory cortex (SSFP) of an anesthetized rat. Forepaw stimulation induced release of ATP in the SSFP region. To interfere with purinergic signaling by promoting rapid breakdown of the vesicular and/or released ATP, a lentiviral vector was used to express a potent ectonucleotidase, transmembrane prostatic acid phosphatase (TMPAP), in the SSFP region. TMPAP expression had no effect on resting cerebral blood flow, cerebrovascular reactivity, and neuronal responses to sensory stimulation. However, TMPAP catalytic activity markedly reduced the magnitude of BOLD fMRI responses triggered in the SSFP region by forepaw stimulation. Facilitated ATP breakdown could result in accumulation of adenosine. However, blockade of $A_{1}$ receptors had no effect on BOLD responses and did not reverse the effect of TMPAP. These results suggest that purinergic signaling plays a significant role in generation of BOLD fMRI signals. We hypothesize that astrocytes activated during periods of enhanced neuronal activity release ATP, which propagates astrocytic activation, stimulates release of vasoactive substances and dilation of cerebral vasculature.

Key words: astrocyte; ATP; BOLD; fMRI; glia; neurovascular coupling

\section{Introduction}

fMRI has significantly advanced our understanding of the human brain. Yet despite widespread application of the fMRI method, the cellular and signaling mechanisms responsible for regional hemodynamic changes underlying generation of the BOLD fMRI signals remain poorly understood (Howarth, 2014).

\footnotetext{
Received Sept. 10, 2014; revised Feb. 5, 2015; accepted Feb. 24, 2015

Author contributions: I.N.C., A.Y.A., S.K., M.F.L., and A.V.G. designed research; J.A.W., I.N.C., P.S.H., R.T.R.H., P.R.A., S.C.C., and A.G.T. performed research; P.V. contributed unpublished reagents/analytic tools; J.A.W., I.N.C., R.T.R.H., A.Y.A., S.K., and A.V.G. analyzed data; I.N.C., S.K., and A.V.G. wrote the paper.

This study was supported by The Wellcome Trust 095064, Medical Research Council Grant 42450, and an MRC Capacity Building Studentship Award MR.G1000411-2/1 to I.N.C. A.V.G is a Wellcome Trust Senior Research Fellow. The authors declare no competing financial interests.

*J.A.W. and I.N.C. contributed equally to this study as joint first authors.

tS.K., M.F.L., and A.V.G. contributed equally to this study as joint last authors.

This article is freely available online through the J Neurosci Author Open Choice option.

Correspondence should be addressed to either of the following: Dr. Sergey Kasparov, School of Physiology and Pharmacology, University of Bristol, Bristol, BS8 1TD, United Kingdom, E-mail: sergey.kasparov@bristol.ac.uk; or Dr. Alexander V. Gourine, Centre for Cardiovascular and Metabolic Neuroscience, Neuroscience, Physiology and Pharmacology, University College London, London, WC1E 6BT, United Kingdom. E-mail: a.gourine@ucl.ac.uk.

DOI:10.1523/JNEUROSCI.3787-14.2015

Copyright $\odot 2015$ the authors $\quad 0270-6474 / 15 / 355284-09 \$ 15.00 / 0$
}

Astrocytes are ubiquitous glial cells that surround all cerebral blood vessels and are thought to provide an essential link between increased neuronal activity and changes in local cerebrovascular blood flow (neurovascular coupling) (Howarth, 2014). Several studies have documented that heightened neuronal activity increases intracellular calcium concentration $\left(\left[\mathrm{Ca}^{2+}\right]_{i}\right)$ in neighboring astrocytes (Hirase et al., 2004; Nimmerjahn et al., 2004; Wang et al., 2006; Di Castro et al., 2011; Panatier et al., 2011; Lind et al., 2013). When $\left[\mathrm{Ca}^{2+}\right]_{i}$ in astrocytes is experimentally raised, changes in cerebral arteriole diameter follow (Mulligan and MacVicar, 2004; Takano et al., 2006; Gordon et al., 2008). Moreover, astrocytic, but not neuronal, $\left[\mathrm{Ca}^{2+}\right]_{\mathrm{i}}$ responses were shown to correlate well with hemodynamic changes as demonstrated in a mouse model (Lind et al., 2013), suggesting that $\mathrm{Ca}^{2+}$ dependent release of vasoactive substances by astrocytes mediates neurovascular coupling (Attwell et al., 2010; Howarth, 2014). However, cerebrovascular responses and BOLD signals are preserved in transgenic mice lacking Type $2 \mathrm{IP}_{3}$ receptors (which mediate astroglial $\mathrm{Ca}^{2+}$ responses triggered by activation of $\mathrm{G}_{\mathrm{q}}{ }^{-}$ coupled receptors) (Nizar et al., 2013; Bonder and McCarthy, 2014; Jego et al., 2014), which argues against any significant role for astrocytes. To the contrary, the most recent data demonstrate 
that $\mathrm{Ca}^{2+}$ signaling in astrocytic processes is fast enough to underlie functional hyperemia (Otsu et al., 2015). Therefore, although there are strong reasons to believe that astrocytes play a role in linking enhanced neuronal activity with cerebrovascular responses and BOLD fMRI signals, more experimental evidence is needed.

An astrocyte has intricate processes that enwrap several neuronal somata and thousands of individual synapses (Bushong et al., 2002). Astrocytes are highly sensitive to ATP, abundantly express ionotropic and metabotropic purinoceptors, and release ATP in response to a variety of stimuli (Coco et al., 2003; Gourine et al., 2010; Huckstepp et al., 2010). Many nonexcitable cells communicate via release of ATP, and ATP is a major signaling molecule of astroglial communication (Bowser and Khakh, 2007; Torres et al., 2012). We reasoned that, if astrocytes play a role in the mechanisms of neurovascular coupling, then blockade of ATP-mediated signaling should have a significant impact on BOLD responses.

In this study, an established stimulation paradigm (electrical forepaw) was applied in experimental studies conducted in anesthetized rats to determine whether ATP (1) is released and (2) contributes to the development of BOLD fMRI responses in the forepaw region of the somatosensory cortex (SSFP). Because astrocytes show abundant expression of many types of purinoceptors, our experimental strategy was not to block specific receptor(s), but to interfere with purinergic signaling altogether by promoting rapid breakdown of the vesicular and/or extracellular pools of ATP, ADP, and AMP in the SSFP region by virally driven overexpression of a potent ectonucleotidase, transmembrane prostatic acid phosphatase (TMPAP).

\section{Materials and Methods}

The experiments were performed in male Sprague Dawley rats in accordance with the European Commission Directive 86/609/EEC (European Convention for the Protection of Vertebrate Animals used for Experimental and Other Scientific Purposes) and the United Kingdom Home Office (Scientific Procedures) Act (1986) with project approval from the Institutional Animal Care and Use Committee.

Anesthetized animal preparation. Rats were anesthetized with isoflurane $(5 \%)$, and depth of anesthesia was assessed by the absence of a response to a paw pinch. The femoral artery and vein were cannulated for measurement of arterial blood pressure and administration of drugs, respectively. Alpha-chloralose was then administered $\left(75 \mathrm{mg} \mathrm{kg}^{-1}\right.$, i.v.), and isoflurane was discontinued. The trachea was cannulated, the head was secured with tooth and ear bars, and the animal was ventilated with

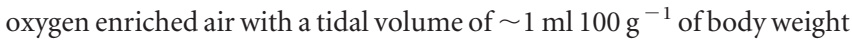
and a ventilator frequency similar to the resting respiratory rate $(\sim 65$ strokes $\left.\mathrm{min}^{-1}\right) . P_{a \mathrm{O} 2}, P_{a \mathrm{CO} 2}$, and $\mathrm{pH}$ of the arterial blood were measured regularly and kept within the physiological ranges by altering tidal volume and/or ventilator frequency. The body temperature was maintained at $37.0 \pm 2{ }^{\circ} \mathrm{C}$. During biosensor recordings and fMRI imaging, the animal was paralyzed with gallamine triethiodide $\left(50 \mathrm{mg} \mathrm{kg}^{-1}\right.$, i.v.; then 10 $\mathrm{mg} \mathrm{kg}^{-1} \mathrm{~h}^{-1}$, i.v.).

ATP biosensor recordings. In six anesthetized rats $(100 \mathrm{~g})$, left and right SSFP regions were exposed following craniotomy and removal of dura mater. Dual recording configuration of an ATP biosensor $(0.5 \mathrm{~mm}$ in length, $50 \mu \mathrm{m}$ in diameter; Sarissa Biomedical) and null biosensor $(0.5$ $\mathrm{mm}$ in length, $50 \mu \mathrm{m}$ in diameter) placed bilaterally in direct contact with the surface of the SSFP cortical area was used (coordinates from bregma: anteroposterior 0.4: -0.65 ; mediolateral 2.4: 3.2; dorsoventral -1.6 : -1.0 ; see Fig. $1 A$ ). The exposed area of the brain and both sensors were covered with PBS containing $2 \mathrm{~mm}$ glycerol (required for ATP biosensor operation) (Llaudet et al., 2005). Unilateral forepaw stimulation $(0.3 \mathrm{~ms}$ pulse width, $3 \mathrm{~Hz}, 3 \mathrm{~mA} 20 \mathrm{~s})$ was applied using an electrical stimulator (Digitimer) controlled by a 1401 interface (Cambridge Electronic Design CED). Biosensors were connected to a potentiostat (Du- ostat ME200+; Sycopel International), and biosensor currents were recorded using 1401 interface and Spike 2 software (CED). Sensors were calibrated with $10 \mu \mathrm{M}$ ATP at the beginning and the end of each experiment (see Fig. 1B). The biosensors were covered with a permselectivity layer that reduces signals from nonspecific electroactive interferents. To assess the integrity of this layer, the sensors were tested using $10 \mu \mathrm{M}$ 5-HT (a potential electroactive interferent) before and after the recordings.

Lentiviral vector for TMPAP overexpression. To interfere with purinergic signaling, a lentiviral vector was generated to overexpresses TMPAP (Zylka et al., 2008) under the control of an elongation factor $1 \alpha(\mathrm{EF} 1 \alpha)$ promoter. Generation of the vector (LVV-EF1 $\alpha$-TMPAP-EGFP) and validation of TMPAP efficacy in blocking ATP-mediated communication between cultured astrocytes have been described in detail previously (Marina et al., 2013). TMPAP is a transmembrane enzyme; and when inserted into a plasma membrane, the catalytic domain faces the extracellular space. It is also expected to be incorporated into the membranes of various vesicular compartments, with the catalytic domain facing the inside of the vesicle where the acidic environment should favor TMPAP catalytic activity. To determine whether TMPAP expression has an effect on purines, which accumulate inside astroglial vesicular compartments, cell cultures were transduced to express TMPAP or enhanced green fluorescent protein (EGFP) and loaded with a fluorescent ATP analog $2^{\prime}, 3^{\prime}$ $\mathrm{O}-\left(\mathrm{N}^{\prime}\right.$-methylanthraniloyl)-ATP (MANT-ATP). Primary astroglial cell cultures were prepared from the cerebral cortices of rat pups (P2-P3) of either sex as described in detail previously (Marriott and Ljungberg, 1995 ) and transduced with either LVV-EF1 $\alpha$-TMPAP-EGFP or a control virus LVV-EF1 $\alpha$-EGFP. MANT-ATP is an ATP analog where either the ribose $2^{\prime}$ hydroxy or the $3^{\prime}$ hydroxy group is esterified by the fluorescent methylisatoic acid and used for studying nucleotide-binding proteins, ATP stores, and mechanisms of ATP vesicular release (Sorensen and Novak, 2001; Kasymov et al., 2013). Cell cultures were incubated with MANT-ATP (50 $\mu \mathrm{M})$ for $4 \mathrm{~h}$ in a DMEM supplemented with $10 \% \mathrm{FCS}$, washed, and then incubated for a further $3.5 \mathrm{~h}$ to allow compartmentalization of MANT-ATP. After loading, cultures were washed 5 times with Hanks balanced salt solution ( $137 \mathrm{~mm} \mathrm{NaCl}, 5.4 \mathrm{~mm} \mathrm{KCl}, 0.25 \mathrm{~mm}$ $\mathrm{Na}_{2} \mathrm{HPO}_{4}, 0.44 \mathrm{mM} \mathrm{KH}_{2} \mathrm{PO}_{4}, 1.3 \mathrm{~mm} \mathrm{CaCl}, 1.0 \mathrm{~mm} \mathrm{MgSO}_{4} 4.2 \mathrm{~mm}$ $\mathrm{NaHCO}_{3}, 10 \mathrm{~mm}$ HEPES, pH 7.4) and examined under a fluorescence microscope. MANT-ATP and EGFP fluorescence were excited at 405 or $488 \mathrm{~nm}$ and collected at $430-480 \mathrm{~nm}$ or $500-530 \mathrm{~nm}$, respectively.

To promote rapid breakdown of the vesicular and/or extracellular pools of ATP, ADP, and AMP, the SSFP region was targeted to overexpress TMPAP (vector LVV-EF1 $\alpha$-TMPAP-EGFP), whereas the contralateral SSFP area was transduced to express EGFP (vector LVV-EF1 $\alpha$ EGFP). The promoter used in these vectors is not cell selective and was expected to be active in both astrocytes and neurons.

Viral gene transfer in vivo. Young adult rats $(160 \mathrm{~g})$ were anesthetized with a mixture of ketamine $\left(60 \mathrm{mg} \mathrm{kg}^{-1}\right.$, i.m.) and medetomidine $(250$ $\mu \mathrm{g} \mathrm{kg}^{-1}$, i.m.) and placed in a stereotaxic frame. The SSFP region was targeted bilaterally with 10 microinjections of viral vectors (LVV-EF $1 \alpha$ TMPAP-EGFP, titre $3-4 \times 10^{9} \mathrm{TU} / \mathrm{ml}$; or LVV-EF1 $\alpha$-EGFP, titre $3-5 \times$ $10^{9} \mathrm{TU} / \mathrm{ml}$ ) between the following coordinates: anteroposterior 0.4 : -0.65; mediolateral 2.4: 3.2; dorsoventral -1.6: -1.0 (from bregma). After the microinjections, the wound was sutured and anesthesia was reversed with atipamezole $\left(1 \mathrm{mg} \mathrm{kg}^{-1}\right)$. Immediate postoperative care was given, and animals were left to recover for 14-21 d before the experiments to ensure a stable and high level of transgene expression. The sides expressing TMPAP and EGFP were randomized between the animals and blinded for the analysis of fMRI, cerebral blood flow (CBF), and electrophysiology datasets.

fMRI imaging. The animal (transduced to express TMPAP and EGFP in the SSFP regions of the cerebral cortex) was anesthetized (induction $5 \%$ isoflurane, maintenance $\alpha$-chloralose $75 \mathrm{mg} \mathrm{kg}^{-1}$, i.v. bolus; supplemented with $30 \mathrm{mg} \mathrm{kg}^{-1} \mathrm{~h}^{-1}$, i.v.), prepared and instrumented as described above, and then transferred to the MRI scanner bed. The head was secured, and the animal was ventilated with oxygen enriched air using an MRI compatible ventilator (CWE). Imaging was performed using a 9.4T Agilent horizontal bore scanner (Agilent). A $72 \mathrm{~mm}$ inner diameter volume coil was used for radio frequency transmission (Rapid Biomedical), and signal was received using a 4 channel array head coil 
A

contralateral

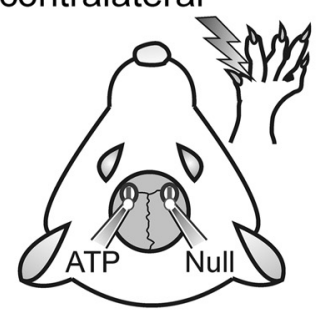

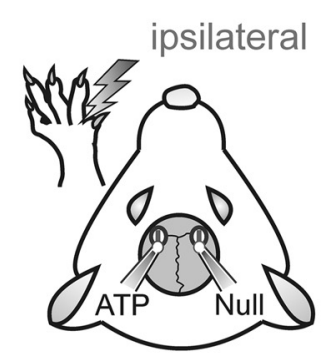

B

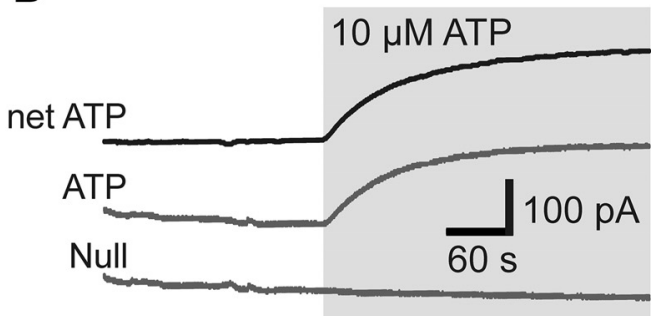

D
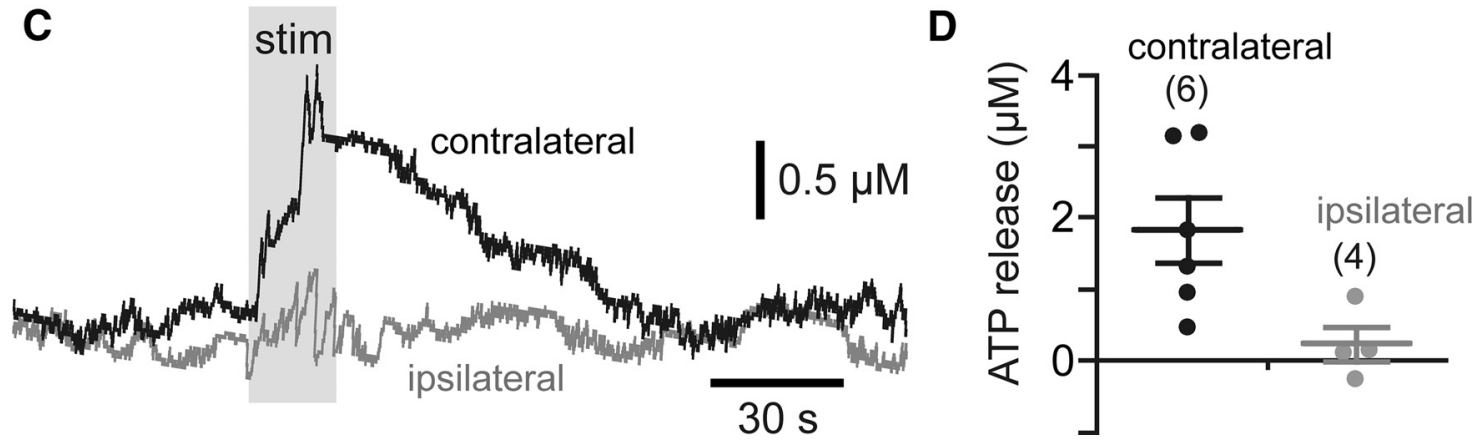

Figure 1. Activation of somatosensory pathways increases extracellular concentration of ATP in the cerebral cortex of an anesthetized rat. $\boldsymbol{A}$, Schematic drawing of the experimental design illustrating positioning of the ATP or null biosensors on the exposed surface of the forepaw region of the SSFP. $\boldsymbol{B}$, Calibration of biosensors illustrating changes in ATP and null sensor currents in response to ATP $(10 \mu \mathrm{m})$. To determine changes in ATP concentration, null sensor currents were subtracted from ATP sensor currents (net-ATP). C, Representative recordings showing changes in ATP concentration within the SSFP region in response to electrical stimulation of the contralateral and ipsilateral paws. $D$, Summary data illustrating peak ATP release triggered in the SSFP region by electrical stimulation of the contralateral $(n=6)$ and the ipsilateral $(n=4)$ paws.

(Rapid Biomedical). A high-resolution anatomical reference scan was acquired using a fast spin echo sequence $\left(\mathrm{TR} / \mathrm{TE}_{\text {eff }}=3100 / 48 \mathrm{~ms}, \mathrm{ETL}=\right.$ 8 , matrix size $=256 \times 256, \mathrm{FOV}=35 \mathrm{~mm} \times 35 \mathrm{~mm}$, 30 slices, $1 \mathrm{~mm}$ slice thickness). fMRI BOLD-weighted images were acquired using a one or two shot gradient echo planar imaging sequences: TE/TR $=15 \mathrm{~ms} / 1500$ $\mathrm{ms}$, matrix size $=64 \times 64, \mathrm{FOV}=35 \times 35 \mathrm{~mm}(n=8)$ or $52.5 \times 52.5$ $\mathrm{mm}(n=3), 8$ slices, slice thickness $=1 \mathrm{~mm}$. The fMRI paradigm for each of the experiments was $120 \mathrm{~s}$ rest followed by $20 \mathrm{~s}$ bilateral forepaw stimulation ( $0.3 \mathrm{~ms}$ pulse width, $3 \mathrm{~Hz}, 1.5 \mathrm{~mA}$ ) (Huttunen et al., 2008) repeated 3 times. This sequence was repeated 6 times for a total of 18 periods of 20-s-long stimulations. In 9 of the 11 rats, $A_{1}$ adenosine receptor antagonist 8-cyclopentyl-1,3-diproplyxanthine (DPCPX, $1 \mathrm{mg} \mathrm{kg}^{-1}$ ) was injected intravenously, and fMRI experiments were repeated. Forepaw stimulations were performed using two electrical stimulators (Digitimer) controlled by a 1401 interface (CED), which was triggered to the first echo planar image acquisition of each fMRI experimental sequence. The current delivered by each stimulator was measured before each the experiments to ensure identical stimulations of both paws. fMRI responses are highly sensitive to many factors, including blood $\mathrm{pH}$, gas tensions, and the level of anesthesia (Austin et al., 2005; Franceschini et al., 2010). To ensure identical conditions when fMRI responses were triggered in hemispheres expressing TMPAP and EGFP, simultaneous bilateral forepaw stimulation was applied.

CBF measurements. Measurements of CBF and cerebrovascular reactivity were performed using arterial spin labeling MRI. A separate cohort of rats was transduced to express TMPAP and EGFP in the SSFP regions. After 14-21 d recovery period, the animals were anesthetized (induction $5 \%$ isoflurane, maintenance $\alpha$-chloralose $75 \mathrm{mg} \mathrm{kg}^{-1}$, i.v. bolus; supplemented with $30 \mathrm{mg} \mathrm{kg}^{-1} \mathrm{~h}^{-1}$, i.v. infusion), instrumented as described above and then transferred to the MRI scanner bed. Baseline cerebral perfusion in the targeted area of the SSFP cortex was mapped using a flow sensitive alternating inversion recovery sequence with a 3 shot segmented gradient echo EPI readout $(\mathrm{TE}=5.8 \mathrm{~ms}, \mathrm{TR}=5 \mathrm{~s}, \mathrm{TI}=2 \mathrm{~s}, 3$ slices, $1 \mathrm{~mm}$ slice thickness). Repeated arterial spin labeling images (acquired every $30 \mathrm{~s}$ ) were captured for $10 \mathrm{~min}$ at baseline conditions, during $5 \mathrm{~min}$ of $\mathrm{CO}_{2}$ challenge ( $5 \% \mathrm{CO}_{2}$ in the inspired gas mixture), and during a $5 \mathrm{~min}$ period of recovery. This experimental protocol was repeated three times for each animal. Maps of CBF were generated by fitting the data to the established model (Buxton et al., 1998). The mean CBF within the SSFP cortical areas targeted to express TMPAP and EGFP was taken from manually drawn ROIs.

Electrophysiology. Electrophysiological recordings were performed to determine whether neuronal activity and neuronal responses to sensory stimulation are affected by TMPAP expression in the SSFP region. Rats were transduced to express TMPAP or EGFP in the SSFP region and prepared using the same surgical approach and monitoring of physiological variables as for the fMRI experiments. The animal was mounted on a stereotaxic frame and cortical surfaces were exposed bilaterally. The dura was pierced and a carbon fiber electrode ( $7 \mu \mathrm{m}$ tip diameter, 300-500 $\mathrm{k} \Omega$, impedance measured at $1 \mathrm{kHz}$ ) was placed in the SSFP region using the following coordinates from bregma: anteroposterior $0 \pm 0.2$; mediolateral $3.0 \pm 0.2$; dorsoventral $-1.0 \pm 0.2$. Signals were amplified and filtered (bandpass $0.2-15 \mathrm{kHz}$ with $50 \mathrm{~Hz}$ notch) using the NeuroLog system (Digitimer) before being digitized (1401 interface, CED) and recorded for offline analysis. Electrical stimulation was applied to a paw as described above while multiunit recordings were made in the contralateral SSFP. To determine the threshold of activation, the amplitude of stimulation was gradually reduced until no field potentials could be detected above the recording noise.

Immunohistochemistry. At the end of all the experiments, rats were transcardially perfused with saline $(0.9 \% \mathrm{NaCl})$, followed by ice-cold PFA (4\%). Brains were postfixed in PFA (4\%) for $24 \mathrm{~h}$, then cryoprotected in sucrose $(30 \%)$ for $12 \mathrm{~h}$, and serially sectioned $(40 \mu \mathrm{M})$ using a freezing microtome. Free-floating sections were washed in PBS and then incubated for $60 \mathrm{~min}$ in $0.3 \%$ Triton X-100 and 10\% FBS followed by overnight incubation with primary antibodies (rabbit anti-GFAP, 1:1000, Dako; or mouse anti-NeuN [hexaribonucleotide binding protein-3] 1:1000, Millipore). Sections were then washed with PBS and incubated for $1 \mathrm{~h}$ at room temperature with secondary antibodies (antirabbit or anti-mouse antibodies conjugated to AlexaFluor-568, Invitrogen). Images were acquired using a fluorescent microscope (Zeiss Imager Z.1, Carl Zeiss).

Data analysis: $f M R I$. The high resolution anatomical reference scan was registered to a rat brain atlas (Schwarz et al., 2006) using Statistical Paramet- 
A

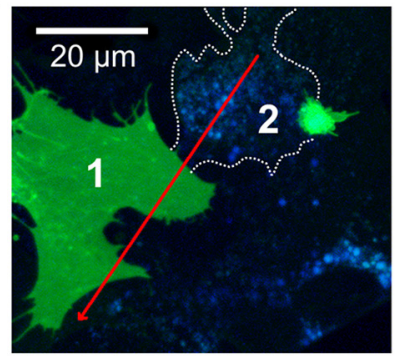

B

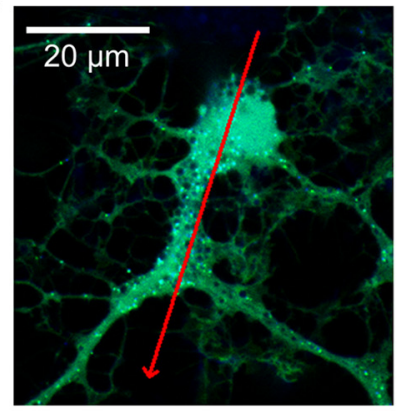

C

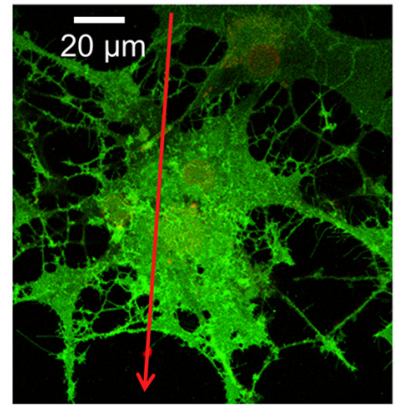

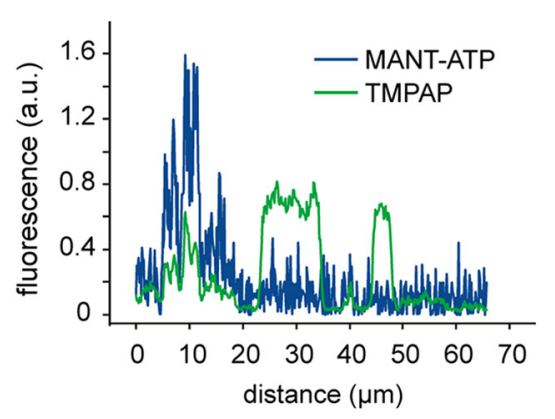
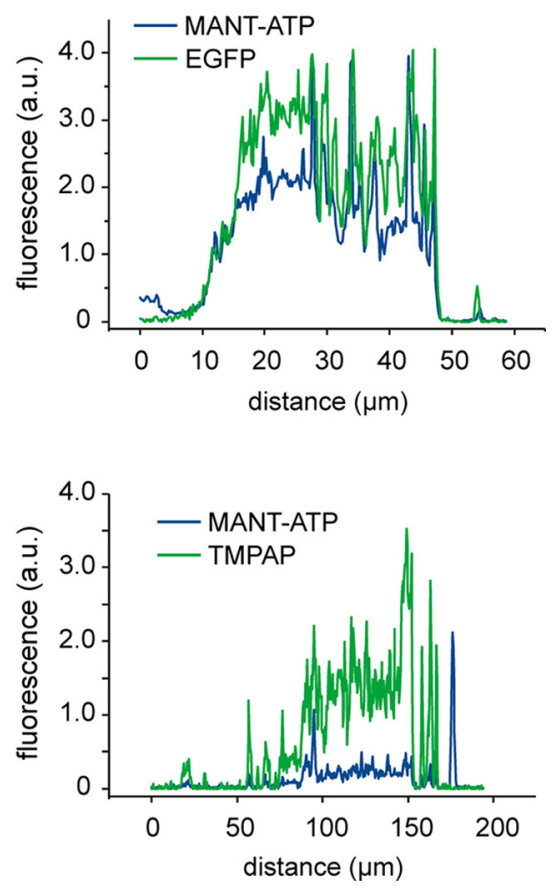

Figure 2. Catalytic activity of TMPAP prevents accumulation of ATP within the intracellular vesicular compartments. $A$, Left, Fluorescent image of astrocytes in the same cell culture showing that TMPAP expression prevents labeling of intracellular vesicular compartments with MANT-ATP. Right, Colocalization line profile following the arrow (red), illustrating intensity of fluorescence of TMPAP-EGFP (green) and MANT-ATP (blue). 1, Cell transduced to express TMPAP. 2, Cell that was not transduced. B, Left, Fluorescent image of a cultured astrocyte transduced to express EGFP displaying abundant labeling of putative ATP-containing vesicles with MANT-ATP. Right, Colocalization line profile following the arrow (red), illustrating intensity of fluorescence of EGFP (green) and MANT-ATP (blue). C, Left, Fluorescent image of cultured astrocytes transduced to express TMPAP-EGFP, showing absence of MANT-ATP vesicular labeling. Right, Colocalization line profile following the arrow (red), illustrating intensity of fluorescence of TMPAP-EGFP (green) and MANT-ATP (blue).

ric Mapping (SPM) (http://www.fil.ion.ucl.ac.uk/spm/software/spm8/) with the same transformation matrix applied to all fMRI images to map the functional data into the standard atlas space. The fMRI images were then flipped horizontally about the midpoint of the brain in the animals where TMPAP-expressing virus was injected in the right hemisphere $(6$ of the 11 rats), for consistent left-right location in the atlas space of the EGFP (right) and TMPAP (left) areas across all the 11 animals. ROIs were taken in the left and right SSFP regions, which are clearly delineated in the atlas, avoiding the need for manual ROI placement. MRI slice locations were chosen to match the stereotaxic coordinates of viral injections (see above) and the thickness $(2 \times 1 \mathrm{~mm})$ corresponded to the fMRI data acquisition and estimated area of transgene expression based on histological analysis. The mean BOLD signal within the SSFP ROIs was normalized for each animal and the mean signal change (\%) from the baseline during $20 \mathrm{~s}$ forepaw stimulations was calculated for the TMPAP and EGFP-expressing areas of each subject. A Wilcoxon signed-rank test was used to evaluate the differences in BOLD responses evoked by forepaw stimulation in the TMPAP- and EGFP-expressing sides. In addition, SPM second level mixed-effects analysis was implemented to map the
BOLD responses to forepaw stimulation. fMRI data were spatially and temporally smoothed ( $0.8 \mathrm{~mm}$ full half-width at maximum) and registered to the rat brain atlas. SPM contrast images were generated by first-level analysis of each subject's time series using an on/off regressor derived from the applied forepaw stimulus paradigm. Contrast images were flipped left/right about the midpoint for consistent TMPAP/EGFP expression sites between the animals. Mixed-effects group analysis was then performed to map regions of concordant BOLD responses to forepaw stimulation across all the animals ( $p<0.05, n=11$, noncorrected). The same analysis was applied to the data obtained in 9 rats, which received DPCPX injections and underwent repeated imaging.

\section{Results}

ATP biosensors were placed in direct contact with the surface of the SSFP cortical area to determine whether ATP is released in response to forepaw stimulation (Fig. 1A). An almost immediate release of ATP was detected within the contralateral SSFP region upon the onset of stimulation (Fig. $1 C)$ that had a mean peak amplitude of $1.8 \pm 0.5 \mu \mathrm{M}(n=6 ; p=0.02$; Fig. $1 D)$. Increases in ATP release were not observed in response to electrical stimulation of the ipsilateral paw (Fig. 1C,D). These data indicate that the extracellular concentration of ATP in the cerebral cortex increases in response to activation of somatosensory pathways.

For further validation of TMPAP's efficacy, primary astroglial cultures were used to determine whether the catalytic activity of TMPAP has an effect on ATP accumulation within the putative secretory vesicular compartments. Cultured astrocytes not expressing TMPAP (Fig. $2 A)$ or transduced to express EGFP (Fig. 2B) displayed abundant punctate fluorescence in the cytosol following incubation with MANT-ATP, which accumulates within the putative ATPcontaining organelles (mean fluorescence $1570 \pm 75$ a.u; $n=27$ cells in 8 cultures). Astrocytes expressing TMPAP were devoid of MANT-ATP staining (mean fluorescence $324 \pm 22$ a.u; $n=21$ cells in 7 cultures; $p<0.001$; Fig. $2 A, C$ ), indicating that TMPAP activity effectively prevents accumulation of ATP within the intracellular vesicular compartments.

Injections of LVV-EF1 $\alpha$-TMPAP-EGFP or LVV-EF $1 \alpha$-EGFP resulted in widespread expression of the respective transgene in the SSFP region (Fig. $3 B, C$ ). The areas of expression were $\sim 1 \times$ $2 \times 2 \mathrm{~mm}$ (Fig. $3 B, C$ ). Surprisingly, despite the use of a noncell-specific promoter $(\mathrm{EF} 1 \alpha)$, the morphology of transduced cells (Fig. $3 D, E$ ) suggested mainly astroglial expression. Indeed, immunohistochemistry failed to identify any significant colocalization between NeuN (neuronal marker) and TMPAP (Fig. 3D), whereas the majority of transduced cells displayed GFAP immunoreactivity (Fig. 3E). 
Electrical forepaw stimulation reliably triggered biphasic BOLD fMRI responses in the SSFP region (Fig. $4 A, B$ ). In control conditions (EGFP expression), both positive BOLD response and poststimulus undershoot were observed (Fig. 4B), which followed a typical temporal profile (Chen and Pike, 2009). Markedly reduced positive BOLD responses were recorded in the SSFP areas transduced to express TMPAP $(p=0.01$; Fig. 4$)$, indicating that TMPAP activity interferes with the mechanisms of neurovascular coupling underlying generation of BOLD fMRI signals.

TMPAP dephosphorylates ATP/ADP/ AMP and may lead to accumulation of adenosine (Zylka et al., 2008). Thus, the observed reduction in BOLD response in the region of TMPAP expression could be confounded by adenosine accumulation and its actions on $\mathrm{A}_{1}$ adenosine receptors, which generally suppress neuronal activity (Cunha, 2001). To block $A_{1}$ receptors, a potent $A_{1}$ adenosine receptor antagonist DPCPX was administered systemically (1 $\mathrm{mg} \mathrm{kg}^{-1}$, i.v.). At this dose, DPCPX is highly effective in blocking $A_{1}$ receptors in the CNS (Vollert et al., 2013). Following DPCPX treatment, BOLD fMRI responses triggered by forepaw stimulation were reduced even further in the hemisphere expressing TMPAP ( $p=0.004$; Fig. $4 B-D$ ), suggesting that the observed effect of TMPAP activity on BOLD response was due to the lack of ATP/ ADP/AMP and not adenosine accumulation following ATP breakdown. Forepaw stimulation-induced BOLD responses triggered in the SSFP regions expressing EGFP were unaffected by systemic blockade of $\mathrm{A}_{1}$ adenosine receptors $(p=0.99)$.

TMPAP activity may result in a sustained reduction of the "ambient" level of extracellular ATP in the targeted area leading to altered resting blood flow (Kur and Newman, 2014). Because the BOLD response is measured as a relative change, higher resting blood flow would be expected to truncate the recorded BOLD response due to a reduced capacity of cerebral vasculature to dilate further during functional hyperemia. Arterial spin labeling MRI was next used to quantify and determine whether resting CBF (a close correlate of vascular tone) and cerebrovascular reactivity (in response to a $\mathrm{CO}_{2}$ challenge) are altered in the SSFP regions transduced to express TMPAP. The mean resting $\mathrm{CBF}$ was similar in the cortical SSFP regions expressing EGFP $(0.68 \pm$ $\left.0.08 \mathrm{mlg}^{-1} \mathrm{~min}^{-1}\right)$ and TMPAP $\left(0.57 \pm 0.06 \mathrm{mlg}^{-1} \mathrm{~min}^{-1} ; p=\right.$ 0.13 ; Fig. 5). These values of resting $\mathrm{CBF}$ are in agreement with that previously recorded in similar experimental conditions (rat under $\alpha$-chloralose anesthesia) (Nakao et al., 2001). Cortical regions expressing EGFP and TMPAP also displayed similar increases in $\mathrm{CBF}$ in response to $\mathrm{CO}_{2}$ challenge (increases in CBF by $42 \pm 4$ and $40 \pm 5 \%$, respectively; $p=0.44$; Fig. 5), suggesting that both resting cerebrovascular tone and the ability of cerebral vasculature to dilate are not affected by TMPAP expression and activity.

Finally, to determine whether TMPAP expression had an effect on neuronal excitability and responsiveness to incoming sensory input, electrophysiological recordings were performed in the SSFP areas expressing TMPAP and contralateral regions express- ing EGFP. Figure $6 A$ shows the mean amplitude of multiunit activity occurring in response to forepaw stimulation in both hemispheres in all the animals $(n=8)$, and Figure $6 B$ shows the integrated data. No significant differences were found between the EGFP- and TMPAP-expressing cortical areas $(p=0.7)$. The activation threshold at which responses were evoked was also not different between the EGFP- and TMPAP-expressing SSFP regions (Fig. $6 C ; p=0.4$ ). These data indicate that neuronal activity and neuronal responses to incoming sensory input are not affected by the catalytic activity of TMPAP.

\section{Discussion}

Precise cellular and signaling mechanisms underlying generation of BOLD fMRI signals remain unclear. Although the initial events clearly depend on neuronal activity, astrocytes are strategically positioned between neurons and cerebral blood vessels, providing an anatomical and functional neurovascular coupling interface. Indeed, the prevailing theory of neurovascular coupling that has dominated the field in recent years proposes that glutamate spillover from the synaptic clefts onto astrocytic perisynaptic processes is a key initial event that links increases in neuronal activity to changes in local cerebrovascular blood flow (Attwell et al., 2010). Downstream events are hypothesized to involve $\mathrm{Ca}^{2+}$-dependent production of prostaglandins and epoxyeicosatrienoic acids (products of arachidonic acid metabolism) by astrocytes, leading to the dilation of cerebral vasculature (Attwell et al., 2010). However, some of the recent evidence does not corroborate this theory.

For example, it appears that mature astrocytes (at least in mice) do not express the appropriate $G_{\mathrm{q}}$-protein coupled metabotropic glutamate receptors (Sun et al., 2013), and blockade of these receptors has no effect on neurovascular coupling (Calcinaghi et al., 2009). Moreover, neurovascular coupling and 
A
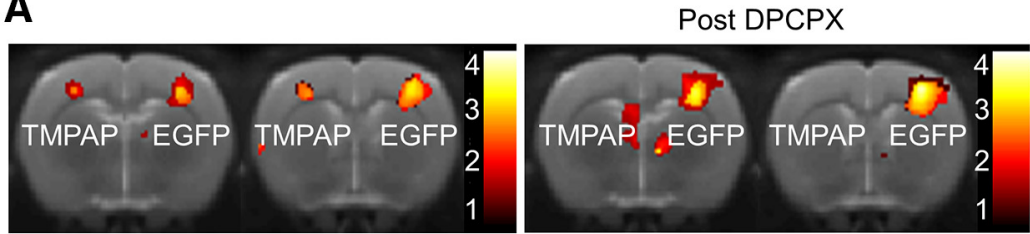

B

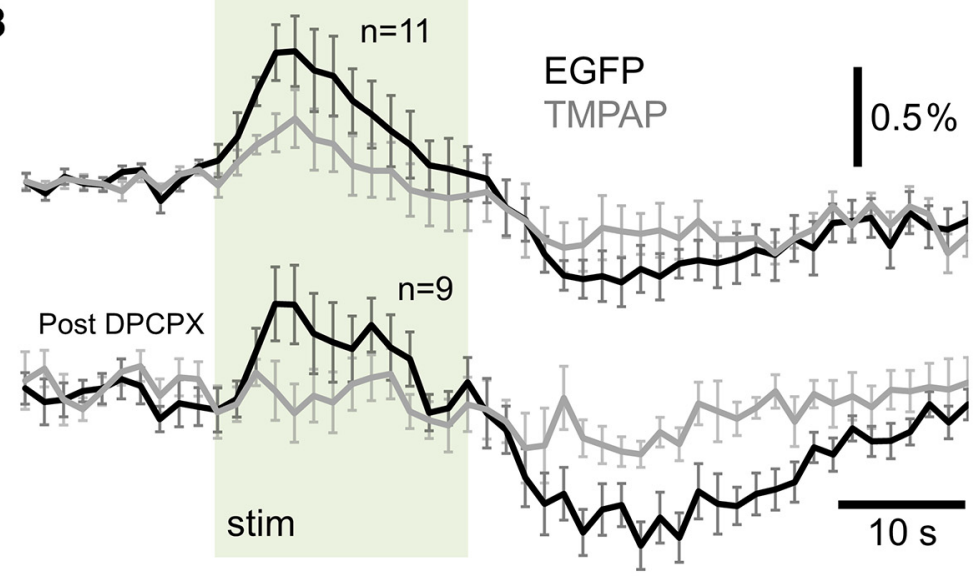

C

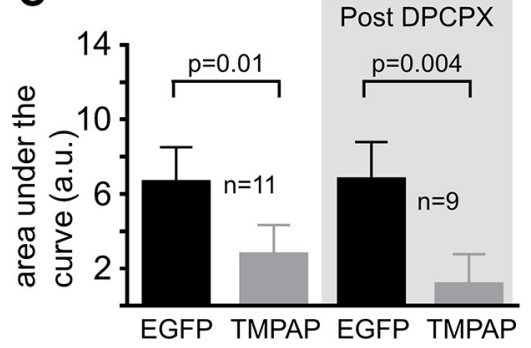

D

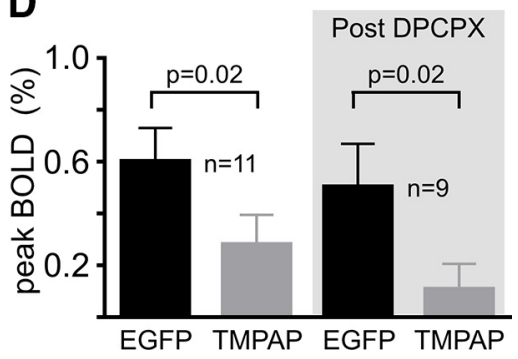

Figure 4. TMPAP expression and activity in the SSFP region reduce the magnitude of BOLD response evoked by electrical forepaw stimulation. $\boldsymbol{A}$, Group-wise activation maps within the SSFP regions expressing TMPAP or EGFP showing mean BOLD responses to $20 \mathrm{~s}$ bilateral electrical forepaw stimulation before and after systemic administration of $A_{1}$ adenosine receptor antagonist DPCPX $\left(1 \mathrm{mg} \mathrm{kg}^{-1}\right)$. The $2 \times 1 \mathrm{~mm}$ consecutive slices. Color bar represents the $t$-score from SPM mixed-effects analysis, $p<0.05$ (uncorrected). $\boldsymbol{B}$, BOLD response curves illustrating changes in mean signal within voxels before and after systemic administration of DPCPX. Black, Dynamics of the electrical forepaw stimulation-induced BOLD response within the SSFP regions expressing EGFP. Gray, Dynamics of the electrical forepaw stimulation-induced BOLD response within the SSFP regions expressing TMPAP. C, D, Summary data (presented as area under the curve and peak of the response) illustrating that TMPAP expression and activity within the SSFP region result in a significant reduction of BOLD FMRI responses evoked by electrical forepaw stimulation. Data are mean \pm SEM. $p$ values from Wilcoxon signed-rank test.

BOLD fMRI responses are not affected in transgenic mice lacking the Type $2 \mathrm{IP}_{3}$ receptors, which mediate astroglial $\mathrm{Ca}^{2+}$ responses to activation of $\mathrm{G}_{\mathrm{q}}$-coupled receptors (Nizar et al., 2013; Bonder and McCarthy, 2014; Jego et al., 2014). It has also been reported that astrocytic $\mathrm{Ca}^{2+}$ responses are too slow to be responsible for the cerebral arteriole dilation (Nizar et al., 2013), although other authors demonstrated that endfeet and somatic $\mathrm{Ca}^{2+}$ elevations in astrocytes precede vascular changes (Lind et al., 2013). The most recent evidence also supports the specific role for $\mathrm{Ca}^{2+}$ signaling in the endfeet (Otsu et al., 2015). The latter study demonstrated that $\mathrm{Ca}^{2+}$ elevations in the astrocytic processes evoked by naturalistic stimuli precede the onset of functional hyperemia by $1-2 \mathrm{~s}$, time sufficient to induce vasodilations when $\left[\mathrm{Ca}^{2+}\right]_{\mathrm{i}}$ elevations are triggered in the endfeet by flash photolysis (Takano et al., 2006).

In the present study, we investigated the possible role of purinergic signaling in the mechanisms underlying generation of BOLD fMRI responses. We reasoned that, although ATP has never been implicated as an important transmitter between cor- tical neurons, it is, without doubt, the paramount signaling molecule that mediates communication between astrocytes. In addition to metabotropic $\mathrm{P} 2 \mathrm{Y}$ receptors, astrocytes also express functional ionotropic P2X receptors (Pankratov et al., 2007) and, therefore, can display $\left[\mathrm{Ca}^{2+}\right]_{\mathrm{i}}$ responses to ATP independently from the recruitment of $\mathrm{IP}_{3}$-mediated pathway(s) (Illes et al., 2012). By extension, blockade of purinergic signaling should reveal the role played by astrocytes in the mechanisms of neurovascular coupling.

First, we demonstrated that the extracellular concentration of ATP in the cerebral cortex increases in response to activation of somatosensory pathways. Because astrocytes express several types of purinoceptors, our subsequent experimental strategy was not to block specific receptor(s), but to interfere with purinergic signaling altogether by promoting rapid breakdown of the vesicular and/or extracellular pools of ATP, ADP, and AMP. Previously, we documented a powerful blocking effect of TMPAP on ATP-mediated $\mathrm{Ca}^{2+}$ waves in cultured astrocytes (Marina et al., 2013). Here we report that expression of TMPAP in astrocytes effectively prevents accumulation of ATP within the intracellular vesicular compartments. This mechanism appears to be particularly powerful because the acidic intravesicular environment should favor the catalytic activity of TMPAP. The forepaw region of the somatosensory cortex was transduced to express TMPAP and the activity of this enzyme effectively reduced the magnitude of the evoked BOLD fMRI responses. This reduction of BOLD magnitude was highly significant, whereas resting $\mathrm{CBF}$, cerebrovascular reactivity, and neuronal responses to incoming sensory input were not affected. Experimental bias was minimized by blinding the investigators to the nature of the transgene, expressed in either side of the cortex.

Increased hydrolysis of ATP/ADP/AMP by TMPAP catalytic activity could raise the extracellular concentration of adenosine. Therefore, the reduced BOLD response in the TMPAP-expressing hemisphere could be explained by adenosine accumulation and adenosine-induced suppression of the neuronal activity. However, the results from our electrophysiological experiments demonstrated no major effect of TMPAP on the neuronal responses to sensory stimuli. Furthermore, systemic $A_{1}$ receptor blockade failed to restore the magnitude of BOLD response, suggesting that the observed effect of TMPAP activity on BOLD signal was not due to adenosine accumulation following facilitated breakdown of ATP and its products. The mean positive BOLD response measured in the hemisphere transduced to express EGFP was similar before and after systemic treatment with DPCPX, indicating that $A_{1}$ adenosine receptor antagonism alone has no effect on neurovascular coupling. 

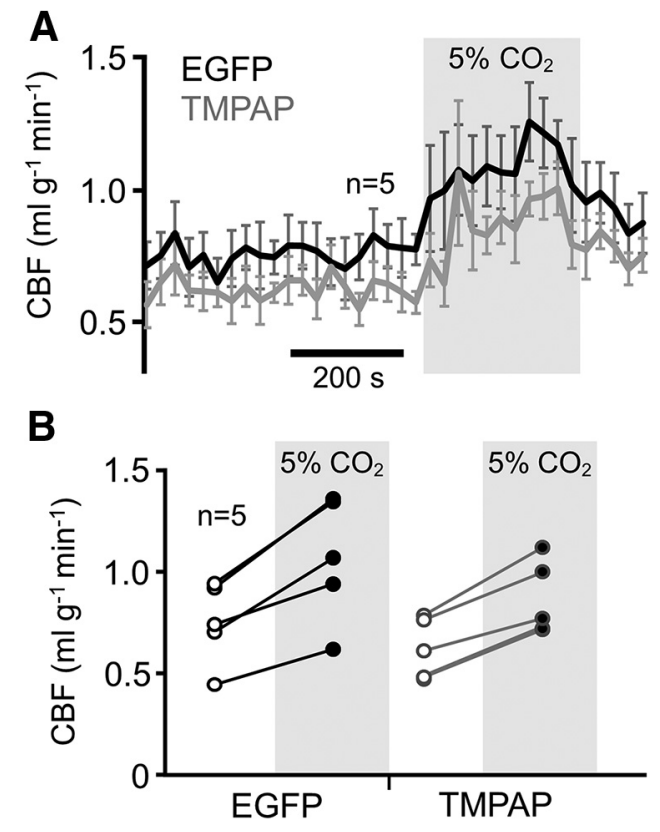

Figure 5. TMPAP activity in the SSFP region does not affect local CBF and cerebrovascular reactivity. $A$, Mean time course of the (BF determined using arterial spin labeling MRI within the SSFP regions transduced to express EGFP (black) and TMPAP (gray) at resting conditions and in response to $\mathrm{CO}_{2}$ challenge $\left(5 \%\right.$ inspired $\left.\mathrm{CO}_{2}\right) . \boldsymbol{B}$, Summary data illustrating resting $\mathrm{CBF}$ and average increases in $\mathrm{CBF}$ in response to $\mathrm{CO}_{2}$ in the SSFP regions expressing EGFP and TMPAP.
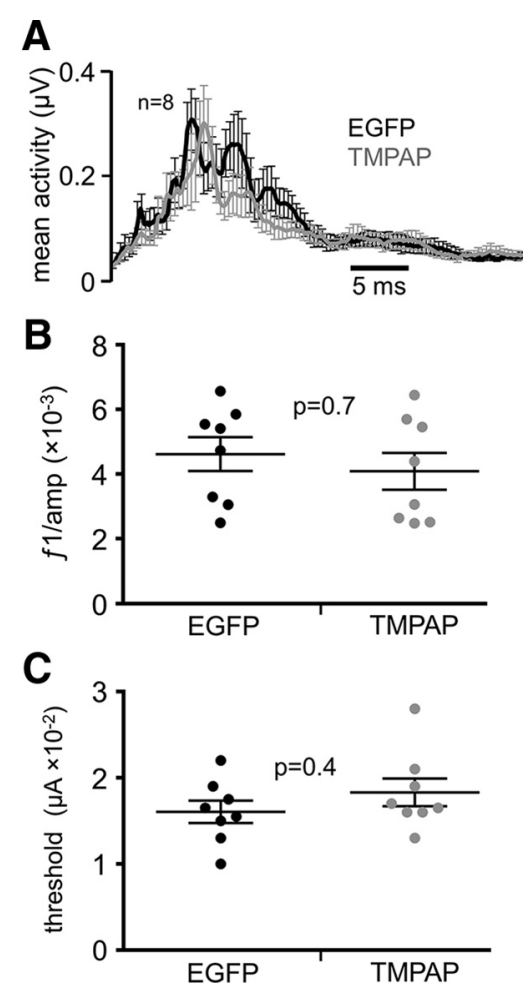

Figure 6. TMPAP expression in the SSFP region does not affect neuronal responses evoked by electrical forepaw stimulation. $\boldsymbol{A}$, Mean amplitudes of multiunit responses evoked by electrical forepaw stimulation $(1.5 \mathrm{~mA}, 3 \mathrm{~Hz}$ ) and recorded in the $S S F P$ regions expressing TMPAP or $\operatorname{EGFP}(n=8)$. B, Summary data showing integrated (area under the curve) multiunit responses evoked by 20 s of electrical forepaw stimulation in the SSFP regions expressing TMPAP or EGFP. C, Summary data illustrating thresholds of electrical forepaw stimulation, required to trigger neuronal activation in the SSFP regions expressing TMPAP or EGFP.
Interestingly, almost complete blockade of the BOLD fMRI response was observed in the hemisphere expressing TMPAP when DPCPX was given systemically. These data are difficult to reconcile with the results of the study by Leithner et al. (2010), which reported that a significant proportion of the BOLD response remains when known pathways hypothesized to be involved in neurovascular coupling are blocked pharmacologically. One possible explanation is that the experimental approach used in the present study targets upstream astrocytic mechanisms/ processes, which activate parallel known and unknown signaling pathways of neurovascular coupling.

The catalytic properties of TMPAP appear to be similar to that of a soluble and secreted form of the enzyme, prostatic acid phosphatase (PAP), although direct comparative analysis of the activities of both enzymes is not available. Despite its name (acid), PAP is active at physiological $\mathrm{pH}$ and displays a flat plateau of activity between $\mathrm{pH} 3$ and $\mathrm{pH} 8$ (Van Etten, 1982). The substrate specificity of this enzyme is very wide; and although it seems to have preference to ADP and AMP (Zylka et al., 2008), it is highly effective in preventing accumulation of ATP within the putative secretory vesicular compartments (present study) and in blocking the spread of $\mathrm{Ca}^{2+}$ excitation between cultured astrocytes (Marina et al., 2013), an effect consistent with blockade of ATPmediated signaling between these cells (Bowser and Khakh, 2007). Rapid degradation of ADP may also be important because $\mathrm{ADP}$ is much more potent than ATP at $\mathrm{P}_{2} \mathrm{Y}_{1}$ receptors (Léon et al., 1997), the main metabotropic P2 receptor expressed by astrocytes (Fields and Burnstock, 2006). There is evidence that ADP contributes to dilation of pial arteries through $\mathrm{P}_{2} \mathrm{Y}_{1}$ receptor activation (Vetri et al., 2011), which is relevant in the current context.

Interestingly, in our experiments, most of the cortical cells transduced to express TMPAP appeared to have astrocytic morphology and displayed GFAP immunoreactivity. This is somewhat surprising given the nonselective nature of the promoter used $(\mathrm{EF} 1 \alpha)$. Nevertheless, this probably was a positive factor because astrocytic endfeet fill all the smallest gaps between neurons and enwrap all the blood vessels, making this experimental approach particularly effective. However, the specific step at which TMPAP activity disrupts neurovascular coupling may not be identified from these experiments. There is evidence that ATP may be released (along with glutamate) at central synapses (Pankratov et al., 2007; Gourine et al., 2008). Release of ATP from axons via volume-activated channels has also been documented (Fields and Ni, 2010). Functional coupling between neuronal and astroglial activities may also occur via local decreases in extracellular $\left[\mathrm{Ca}^{2+}\right]$, which, via opening of connexin hemichannels, lead to the release of ATP (Torres et al., 2012). Therefore, TMPAP activity could suppress ATP-mediated neuron-to-astrocyte signaling or ATP-mediated spread of $\mathrm{Ca}^{2+}$ excitation among astroglial networks. Both would be expected to have an effect on astrocytic release of vasoactive substances, resulting in compromised vascular responses and hence smaller BOLD fMRI signals.

It is also possible that ATP is involved in communication between astrocytes and the blood vessels. The role of purinergic signaling in the control of vascular tone has been previously investigated in the retina (Metea and Newman, 2006). More recently, it was shown in vivo that tonic ATP release maintains retinal vascular tone, via activation of $\mathrm{P}_{2} \mathrm{X}_{1}$ receptors on smooth muscle cells (Kur and Newman, 2014). Another study examined the role of ATP and ATP breakdown products in the mechanisms of pial arteriolar dilation (Vetri et al., 2011) and demonstrated that ADP, AMP, as well as adenosine contribute to neural 
activity-dependent pial arteriolar dilation (Vetri et al., 2011). Thus, it appears that ATP and all products of extracellular ATP hydrolysis are vasoactive and may contribute to the cerebrovascular responses triggered by enhanced neuronal activity.

In conclusion, the results of the present study suggest that purinergic signaling plays an important role in the mechanisms underlying generation of BOLD fMRI responses. Our hypothesis is that ATP released by astrocytes during periods of enhanced neuronal activity acts as a paracrine/autocrine signal amplifier to trigger release of vasoactive substances responsible for the dilation of cerebral vasculature. Concurrent with the recent data obtained in the retina (Kur and Newman, 2014), we propose a fundamental physiological role for purinergic signaling in local activity-dependent regulation of cerebrovascular tone.

\section{Limitations}

In this study, the mechanisms underlying generation of BOLD fMRI responses were studied in rats under $\alpha$-chloralose anesthesia. There is evidence that certain anesthetics (ketamine/xylazine, isoflurane, and urethane) may selectively disrupt astrocytic calcium signaling (Thrane et al., 2012). Assuming $\alpha$-chloralose has the same effect, it is possible that astrocytic calcium signaling is affected under the anesthetic conditions used in this study. While anesthesia is known to have an impact on the magnitude of the evoked BOLD responses (Franceschini et al., 2010; Masamoto and Kanno, 2012), neurovascular coupling has been found to be robustly maintained when $\alpha$-chloralose is used to maintain general anesthesia (Ueki et al., 1992; Masamoto and Kanno, 2012). In the present study we demonstrate release of ATP (primary signaling molecule of astrocytes), BOLD fMRI responses and intact cerebrovascular responses to $\mathrm{CO}_{2}$ in the somatosensory cortex of $\alpha$-chloralose-anesthetized rats allowing study of the fundamental mechanisms underlying the role of astrocytes in the mechanisms of neurovascular coupling. Finally, the experiments described in this report investigated the mechanisms of BOLD fMRI responses in the cerebral cortex. These findings may not necessarily translate to other brain regions considering that the signaling mechanisms of neurovascular coupling may be different in different parts of the CNS (Sloan et al., 2010).

\section{References}

Attwell D, Buchan AM, Charpak S, Lauritzen M, Macvicar BA, Newman EA (2010) Glial and neuronal control of brain blood flow. Nature 468:232243. CrossRef Medline

Austin VC, Blamire AM, Allers KA, Sharp T, Styles P, Matthews PM, Sibson NR (2005) Confounding effects of anesthesia on functional activation in rodent brain: a study of halothane and alpha-chloralose anesthesia. Neuroimage 24:92-100. CrossRef Medline

Bonder DE, McCarthy KD (2014) Astrocytic Gq-GPCR-linked IP ${ }_{3} \mathrm{R}$ dependent $\mathrm{Ca}^{2+}$ signaling does not mediate neurovascular coupling in mouse visual cortex in vivo. J Neurosci 34:13139-13150. CrossRef Medline

Bowser DN, Khakh BS (2007) Vesicular ATP is the predominant cause of intercellular calcium waves in astrocytes. J Gen Physiol 129:485-491. CrossRef Medline

Bushong EA, Martone ME, Jones YZ, Ellisman MH (2002) Protoplasmic astrocytes in CA1 stratum radiatum occupy separate anatomical domains. J Neurosci 22:183-192. Medline

Buxton RB, Frank LR, Wong EC, Siewert B, Warach S, Edelman RR (1998) A general kinetic model for quantitative perfusion imaging with arterial spin labeling. Magn Reson Med 40:383-396. CrossRef Medline

Calcinaghi N, Jolivet R, Wyss MT, Zunzunegui C, Gasparini F, Buck A, Weber B (2009) Blockade of the metabotropic glutamate receptor mGluR5 does not affect neurovascular coupling in adult Sprague-Dawley rats. Glia 57:S124.

Chen JJ, Pike GB (2009) Origins of the BOLD post-stimulus undershoot. Neuroimage 46:559-568. CrossRef Medline
Coco S, Calegari F, Pravettoni E, Pozzi D, Taverna E, Rosa P, Matteoli M, Verderio C (2003) Storage and release of ATP from astrocytes in culture. J Biol Chem 278:1354-1362. CrossRef Medline

Cunha RA (2001) Adenosine as a neuromodulator and as a homeostatic regulator in the nervous system: different roles, different sources and different receptors. Neurochem Int 38:107-125. CrossRef Medline

Di Castro MA, Chuquet J, Liaudet N, Bhaukaurally K, Santello M, Bouvier D, Tiret P, Volterra A (2011) Local $\mathrm{Ca}^{2+}$ detection and modulation of synaptic release by astrocytes. Nat Neurosci 14:1276-1284. CrossRef Medline

Fields RD, Burnstock G (2006) Purinergic signalling in neuron-glia interactions. Nat Rev Neurosci 7:423-436. CrossRef Medline

Fields RD, Ni Y (2010) Nonsynaptic communication through ATP release from volume-activated anion channels in axons. Sci Signal 3:ra73. CrossRef Medline

Franceschini MA, Radhakrishnan H, Thakur K, Wu W, Ruvinskaya S, Carp S, Boas DA (2010) The effect of different anesthetics on neurovascular coupling. Neuroimage 51:1367-1377. CrossRef Medline

Gordon GR, Choi HB, Rungta RL, Ellis-Davies GC, MacVicar BA (2008) Brain metabolism dictates the polarity of astrocyte control over arterioles. Nature 456:745-749. CrossRef Medline

Gourine AV, Dale N, Korsak A, Llaudet E, Tian F, Huckstepp R, Spyer KM (2008) Release of ATP and glutamate in the nucleus tractus solitarii mediate pulmonary stretch receptor (Breuer-Hering) reflex pathway. J Physiol 586:3963-3978. CrossRef Medline

Gourine AV, Kasymov V, Marina N, Tang F, Figueiredo MF, Lane S, Teschemacher AG, Spyer KM, Deisseroth K, Kasparov S (2010) Astrocytes control breathing through $\mathrm{pH}$-dependent release of ATP. Science 329:571-575. CrossRef Medline

Hirase H, Qian LF, Bartho P, Buzsaki G (2004) Calcium dynamics of cortical astrocytic networks in vivo. PLoS Biol 2:494-499. CrossRef Medline

Howarth C (2014) The contribution of astrocytes to the regulation of cerebral blood flow. Front Neurosci 8:103. CrossRef Medline

Huckstepp RT, id Bihi R, Eason R, Spyer KM, Dicke N, Willecke K, Marina N, Gourine AV, Dale N (2010) Connexin hemichannel-mediated $\mathrm{CO}_{2-}$ dependent release of ATP in the medulla oblongata contributes to central respiratory chemosensitivity. J Physiol 588:3901-3920. CrossRef Medline

Huttunen JK, Gröhn O, Penttonen M (2008) Coupling between simultaneously recorded BOLD response and neuronal activity in the rat somatosensory cortex. Neuroimage 39:775-785. CrossRef Medline

Illes P, Verkhratsky A, Burnstock G, Franke H (2012) P2X receptors and their roles in astroglia in the central and peripheral nervous system. Neuroscientist 18:422-438. CrossRef Medline

Jego P, Pacheco-Torres J, Araque A, Canals S (2014) Functional MRI in mice lacking IP3-dependent calcium signaling in astrocytes. J Cereb Blood Flow Metab 34:1599-1603. CrossRef Medline

Kasymov V, Larina O, Castaldo C, Marina N, Patrushev M, Kasparov S, Gourine AV (2013) Differential sensitivity of brainstem versus cortical astrocytes to changes in $\mathrm{pH}$ reveals functional regional specialization of astroglia. J Neurosci 33:435-441. CrossRef Medline

Kur J, Newman EA (2014) Purinergic control of vascular tone in the retina. J Physiol 592:491-504. CrossRef Medline

Leithner C, Royl G, Offenhauser N, Füchtemeier M, Kohl-Bareis M, Villringer A, Dirnagl U, Lindauer U (2010) Pharmacological uncoupling of activation induced increases in $\mathrm{CBF}$ and $\mathrm{CMRO} 2$. J Cereb Blood Flow Metab 30:311-322. CrossRef Medline

Léon C, Hechler B, Vial C, Leray C, Cazenave JP, Gachet C (1997) The P2Y receptor is an ADP receptor antagonized by ATP and expressed in platelets and megakaryoblastic cells. FEBS Lett 403:26-30. CrossRef Medline

Lind BL, Brazhe AR, Jessen SB, Tan FC, Lauritzen MJ (2013) Rapid stimulus-evoked astrocyte $\mathrm{Ca}^{2+}$ elevations and hemodynamic responses in mouse somatosensory cortex in vivo. Proc Natl Acad Sci U S A 110: E4678-E4687. CrossRef Medline

Llaudet E, Hatz S, Droniou M, Dale N (2005) Microelectrode biosensor for real-time measurement of ATP in biological tissue. Anal Chem 77:32673273. CrossRef Medline

Marina N, Tang F, Figueiredo M, Mastitskaya S, Kasimov V, Mohamed-Ali V, Roloff E, Teschemacher AG, Gourine AV, KasparovS (2013) Purinergic signalling in the rostral ventro-lateral medulla controls sympathetic drive and contributes to the progression of heart failure following myocardial infarction in rats. Basic Res Cardiol 108:317-327. CrossRef Medline 
Marriott DR, Ljungberg MC (1995) Neural cell culture: a practical approach. Oxford: Oxford University.

Masamoto K, Kanno I (2012) Anesthesia and the quantitative evaluation of neurovascular coupling. J Cereb Blood Flow Metab 32:1233-1247. CrossRef Medline

Metea MR, Newman EA (2006) Glial cells dilate and constrict blood vessels: a mechanism of neurovascular coupling. J Neurosci 26:2862-2870. CrossRef Medline

Mulligan SJ, MacVicar BA (2004) Calcium transients in astrocyte endfeet cause cerebrovascular constrictions. Nature 431:195-199. CrossRef Medline

Nakao Y, Itoh Y, Kuang TY, Cook M, Jehle J, Sokoloff L (2001) Effects of anesthesia on functional activation of cerebral blood flow and metabolism. Proc Natl Acad Sci U S A 98:7593-7598. CrossRef Medline

Nimmerjahn A, Kirchhoff F, Kerr JN, Helmchen F (2004) Sulforhodamine 101 as a specific marker of astroglia in the neocortex in vivo. Nat Methods 1:31-37. CrossRef Medline

Nizar K, Uhlirova H, Tian P, Saisan PA, Cheng Q, Reznichenko L, Weldy KL, Steed TC, Sridhar VB, MacDonald CL, Cui J, Gratiy SL, Sakadzić S, Boas DA, Beka TI, Einevoll GT, Chen J, Masliah E, Dale AM, Silva GA, et al. (2013) In vivo stimulus-induced vasodilation occurs without IP3 receptor activation and may precede astrocytic calcium increase. J Neurosci 33:8411-8422. CrossRef Medline

Otsu Y, Couchman K, Lyons DG, Collot M, Agarwal A, Mallet JM, Pfrieger FW, Bergles DE, Charpak S (2015) Calcium dynamics in astrocyte processes during neurovascular coupling. Nat Neurosci 18:210-218. CrossRef Medline

Panatier A, Vallée J, Haber M, Murai KK, Lacaille JC, Robitaille R (2011) Astrocytes are endogenous regulators of basal transmission at central synapses. Cell 146:785-798. CrossRef Medline

Pankratov Y, Lalo U, Verkhratsky A, North RA (2007) Quantal release of ATP in mouse cortex. J Gen Physiol 129:257-265. CrossRef Medline

Schwarz AJ, Danckaert A, Reese T, Gozzi A, Paxinos G, Watson C, Merlo-Pich EV, Bifone A (2006) A stereotaxic MRI template set for the rat brain with tissue class distribution maps and co-registered anatomical atlas: application to pharmacological MRI. Neuroimage 32:538-550. CrossRef Medline

Sloan HL, Austin VC, Blamire AM, Schnupp JW, Lowe AS, Allers KA, Matthews PM, Sibson NR (2010) Regional differences in neurovascular coupling in rat brain as determined by fMRI and electrophysiology. Neuroimage 53:399-411. CrossRef Medline

Sorensen CE, Novak I (2001) Visualization of ATP release in pancreatic acini in response to cholinergic stimulus: use of fluorescent probes and confocal microscopy. J Biol Chem 276:32925-32932. CrossRef Medline

Sun W, McConnell E, Pare JF, Xu Q, Chen M, Peng W, Lovatt D, Han X, Smith Y, Nedergaard M (2013) Glutamate-dependent neuroglial calcium signaling differs between young and adult brain. Science 339:197200. CrossRef Medline

Takano T, Tian GF, Peng W, Lou N, Libionka W, Han X, Nedergaard M (2006) Astrocyte-mediated control of cerebral blood flow. Nat Neurosci 9:260-267. CrossRef Medline

Thrane AS, Rangroo Thrane V, Zeppenfeld D, Lou N, Xu Q, Nagelhus EA, Nedergaard M (2012) General anesthesia selectively disrupts astrocyte calcium signaling in the awake mouse cortex. Proc Natl Acad Sci U S A 109:18974-18979. CrossRef Medline

Torres A, Wang F, Xu Q, Fujita T, Dobrowolski R, Willecke K, Takano T, Nedergaard M (2012) Extracellular $\mathrm{Ca}^{2+}$ acts as a mediator of communication from neurons to glia. Sci Signal 5:ra8. CrossRef Medline

Ueki M, Mies G, Hossmann KA (1992) Effect of alpha-chloralose, halothane, pentobarbital and nitrous oxide anesthesia on metabolic coupling in somatosensory cortex of rat. Acta Anaesthesiol Scand 36:318-322. CrossRef Medline

Van Etten RL (1982) Human prostatic acid phosphatase: a histidine phosphatase. Ann N Y Acad Sci 390:27-51. CrossRef Medline

Vetri F, Xu H, Mao L, Paisansathan C, Pelligrino DA (2011) ATP hydrolysis pathways and their contributions to pial arteriolar dilation in rats. Am J Physiol Heart Circ Physiol 301:H1369-H1377. CrossRef Medline

Vollert C, Forkuo GS, Bond RA, Eriksen JL (2013) Chronic treatment with DCPCX, an adenosine $A_{1}$ antagonist, worsens long-term memory. Neurosci Lett 548:296-300. CrossRef Medline

Wang X, Lou N, Xu Q, Tian GF, Peng WG, Han X, Kang J, Takano T, Nedergaard M (2006) Astrocytic $\mathrm{Ca}^{2+}$ signaling evoked by sensory stimulation in vivo. Nat Neurosci 9:816-823. CrossRef Medline

Zylka MJ, Sowa NA, Taylor-Blake B, Twomey MA, Herrala A, Voikar V, Vihko P (2008) Prostatic acid phosphatase is an ectonucleotidase and suppresses pain by generating adenosine. Neuron 60:111-122. CrossRef Medline 